\title{
Epigenetic and Environmental Risk Factors in Skin Cancer
}

\author{
Esra Pancar Yuksel (Corresponding author) \\ Ondokuz Mayis University, Faculty of Medicine, \\ Department of Skin and Venereal Diseases, Samsun, Turkey \\ E-mail: esrapancar@yahoo.com
}

\begin{abstract}
Epigenetic mechanisms cause changes in gene expression and cell phenotype without DNA sequence changes. They have been reported to play role in skin cancers, and identified as DNA methylation, histone modifications and microRNAs. Skin cancer is one of the most common types of cancer in humans and squamous cell carcinoma, basal cell carcinoma, and melanoma are three main types. There are many environmental risk factors for skin cancer such as ultraviolet radiation, ionizing radiation, viruses. Chronic ultraviolet exposure is accepted as the most important one. Environmental factors including ultraviolet radiation have also been reported to cause epigenetic modifications. This review will introduce the role of epigenetic in skin cancer, environmental risk factors in skin cancer and epigenetic modifications caused by these environmental risk factors.
\end{abstract}

Keywords: DNA methylation, environmental risk factor, epigenetic, histone modification, microRNAs, skin cancer

\section{Special Issue of Health Sciences}

DOI: $10.7176 / \mathrm{JSTR} / 6-03-21$

\section{Deri Kanserlerinde Epigenetik ve Çevresel Risk Faktörleri}

\begin{abstract}
Giriş
Epigenetik DNA'nın diziliminde herhangi bir değişiklik olmaksızın genetik bilginin açığa çıkmasında meydana gelen değişikliklerdir. Aynı DNA'ya sahip tek yumurta ikizlerinin aynı yaşa geldiklerinde nasıl oluyor da birisi birçok hastalıkla mücadele ederken, diğeri sağlıklı şekilde sporunu yapabiliyor sorusunun cevabı epigenetik ile verilmiştir. Genetik bilgimizin kodlandığı DNA üzerinde, bir kromozomun belirli bir kısmını oluşturan nükleotid dizisi olarak tanımlanan çok sayıda gen vardır. Hangi genin ne zaman ve nerede aktif hale geleceğini düzenleyen ise epigenetik mekanizmalardır. Epigenetik mekanizmalar tümör süpresör genleri baskılar, onkogenleri aktif hale getirirler ise kansere yol açabilmektedir (Greenberg et al., 2014; Kürekçi et al., 2017; Saha et al.,2013).

Deri kanserlerinde de epigenetik mekanizmaların rol oynadığı tespit edilmiştir ve bunlar DNA metilasyonu, histon modifikasyonları ve mikroRNA'lar olarak tanımlanmıştır (Greenberg et al., 2014; Kürekçi et al., 2017; Saha et al.,2013; Sang and Deng, 2013) . DNA metilasyonu, DNA metiltransferaz tarafından ilgili genin promoter bölgesindeki sitozin halkasına metil grubunun eklenmesi ile gerçekleşir. Hipermetilasyon ile ilgili gen baskılanır (Sang and Deng, 2013) . Promoter bölgesinin hipermetilasyonunun melanomda yer aldığını gösteren çalışmalar bulunmaktadır (Moran et al., 2018) . Guo ve ark. (2019) tarafindan yapılan metaanalizde, melanomda 50 genin promoter bölgesinin metilasyonunun melanom riski ile ilişkili olduğu tespit edilmiştir. Bunlardan CLDN11, MGMT, p16, RAR- $\beta 2$, ve RASSF1A hipermetilasyonu melanom için bir risk faktörü ve potansiyel bir biyobelirteç olarak bildirilmiştir. DNA hipermetilasyonunun skuamöz hücreli karsinom ve bazal hücreli karsinomda da rol oynadığını bildiren çalışmalar vardır. Tümör süpresör genlerden özellikle CDH1'in promoter bölgesinin hipermetilasyonu skuamöz hücreli karsinom (SHK)da gösterilmiştir Murao et al., 2006) .
\end{abstract}


Bazal hücreli karsinom (BHK)da da SHH and WNT yolaklarında promoter hipermetilasyonunun sık olduğu bulunmuştur (Brinkhuizen et al., 2012).

Deri kanserlerinde rol oynayan bir diğer epigenetik mekanizma histon modifikasyonudur. Histon metilasyonu, asetilasyonu ve deasetilasyonu şeklinde gerçekleşir. Histon metilasyonu histon kuyruklarındaki lizin ve arjinine metil eklenmesi sonucu oluşur. Metillenen bölgeye veya eklenen metil sayısına göre gen aktif veya inaktif hale gelir (Audia and Campbell, 2016). Histon asetilasyonu ise histon asetiltransferaz tarafından gerçekleştirilir. Histon kuyruklarına asetil gruplarının eklenmesi ile histonların DNA'ya afinitesi azalır, kromatin açılır, gen aktive olur (Moran et al., 2018). Histon deasetilaz enziminin rol oynadığı histon deasetilasyonunda ise histonların DNA'ya afinitesi artar, kromatin kapanır, gen baskılanır (Penta et al.,2018). Melanomda histon deasetilaz ve metiltransferazların patojenik rol oynadığ tespit edilmiştir (Flørenes et al.,2004; Lee et al., 2014; Garcia-Peterson et al., 2017; Ceol et al., 2011).

Kodlamayan RNA parçacıkları olan mikroRNA(miR)'lar deri kanserlerinde rol oynayan epigenetik mekanizmalardan diğeridir. mRNA'ya bağlanarak transkripsiyonu engellerler (Greenberg et al., 2014). Yapılan çalışmalarda miR-221/-222 ve miR-29c'nin melanom progresyonunda rol oynadığ bildirilmiştir (Felicetti et al., 2008; Nguyen et al., 2011). Primer lezyonda artmış miR-21 and miR-155 tespit edilmesinin ise pozitif sentinel lenf nodu biyopsisi ile ilişkili olduğu bulunmuştur (Grignol et al., 2011). Toll ve ark. (2016) ise kodlamayan RNA Mir-204'ün aktinik keratozun skuamöz hücreli karsinoma ilerlemesinde rol oynadığını bildirmiştir.

Deri kanserinin etiyolojisinde birçok çevresel faktörün rol oynadığı bilinmektedir. Yapılan son çalışmalarda ise bu çevresel faktörlerin epigenetik değişikliklere neden olarak deri kanserine yol açtıkları tespit edilmiştir. Bu çevresel faktörler arasında ultraviyole ışınları, iyonize radyasyon, sigara, ilaçlar yer almaktadır. Ultraviyole (UV) 1şılları melanom, SKH, BHK'nin primer nedenidir. UV maruziyeti, özellikle ağrılı büllü güneş yanıkları SHK, BHK ve melanom gelişim riskini arttırır (Kennedy et al.,2003). Çocukluk döneminde yoğun UV maruziyetinin de melanom riskini arttırdığ bilinmektedir (Whiteman et al., 2001). UV ışınları UVA, UVB ve UVC olarak üçe ayrılmaktadır. UVA, dünya yüzeyine gelen UV'nin yaklaşık \%90'ını oluşturur. Uzun dalga boylu, düşük enerjilidir ve camdan geçer. UVB ise dünya yüzeyine gelen UV'nin yaklaşık \%10'unu oluştururken, kısa dalga boylu, yüksek enerjilidir, camdan geçmez. UVC ozon tabakası tarafindan tutulur. Ozon tabakasının hasarlanması ise yeryüzüne ulaşan UV'nin artmasına neden olmaktadır (Narayaman et al., 2010). UV ışınlarının dünya yüzeyindeki yoğunluğunu etkileyen faktörler bulunmaktadır. Ekvatora yakın yerlerde UV seviyesi artar. Yükseklik arttıç̧a UV maruziyeti artar. Her 1000 metrede UV yoğunluğu \%10 artmaktadır. Gün ortası ve yaz aylarında UV yoğunluğu daha fazladır ve saat 10.00-16.00 arası UVB en yüksek seviyelere ulaşır. Bulut, sis UV seviyelerinin azalmasına neden olur. Yoğun bitki örtüsünün olduğu bölgede gölge daha yoğundur ve UV seviyelerini \%50-95 oranında azaltabilir (Kennedy et al.,2003; Whiteman et al., 2001; Narayaman et al., 2010). Hem UVB hem de UVA deri kanserine neden olmaktadır. UVB, DNA tarafından absorbe edilir, siklobutan primidin dimer oluşumuna neden olarak direkt DNA hasarına yol açar. UVA ise reaktif oksijen türleri oluşturarak indirekt DNA hasarı oluşturur. Bunların sonucunda delesyon, mutasyon ve epigenetik değişiklikler oluşarak deri kanserine neden olurlar (Yang et al.,2019; Archier et al., 2012). Tedavi amaçlı kullanılan fototerapi de deri kanseri açısından risk oluşturmaktadır. PUVA ile tedavi edilen hastalarda SHK ve melanom riski arttığı bilinmektedir. db-UVB'ye maruz kalma ile deri kanserleri arasındaki ilişki henüz tam olarak kanıtlanamamış olmakla beraber db-UVB tedavisi alan hastalarda da deri kanseri geliştiğini bildiren çalışmalar mevcuttur (Archier et al., 2012; Nijsten and Stern, 2003; Maiorino et al., 2016). Solaryum, doğal kaynaktan çok daha fazla miktarda UVA yayar, melanom, BHK, SHK riskini arttırır (Nilsen et al., 2016; Autier and Doré, 2019).

Uranyum madenlerinde çalışanlar, radyologlar, girişimsel kardiyologlar, radyoterapi alanlar iyonize radyasyon açısından risk grubunu oluşturur. İyonize radyasyon DNA hasarına ve DNA metilasyonuna neden olarak özellikle BHK riskini arttırır (Li and Athar, 2016; Miousse et al., 2017). Radon, doğadaki elementlerin diğer elementlere dönüşmesi sırasında oluşarak topraktan, kayalardan açığa çıkan bir gazdır. Havadaki partiküllere yapışan radon elektrostatik etkiyle deriye yapışır. DNA metilasyonuna neden olur. BHK,SHK riskinin arttırır (Vienneau et al., 2017; de Vocht et al., 2019). Polisiklik aromatik hidrokarbonlar en yaygın ve tehlikeli organik kirleticiler arasındadır. Baca temizleyicilerinde kanserojen olarak polisiklik aromatik hidrokarbonun görüldüğü skrotumda SHK bildirilmiştir. Benzo(a)piren nonmelanom kanser nedenleri arasında yer alan polisiklik aromatik hidrokarbondur (Puri et al., 2017). Çevre kirliliğinin DNA metilasyonunda değişikliklere neden olduğu tespit edilmiştir (Silva et al., 2019). Sigaranın SHK için risk faktörü olduğu, melanomda da sentinal lenf nodu metastazı ile sigara içimi arasında ilişki bulunduğu bildirilmiştir (Ortiz and Grando, 2012; Wu et al., 2016; Jones et al., 2017). Joehanes ve ark.(2016) tarafindan yürütülen metaanalizde sigara içmenin ise genomda metilasyon üzerinde etkisi olduğu tespit edilmiştir. 
Deri kanseri için çevresel risk faktörleri arasında yer alan arsenik de non-melanom deri kanseri riskini arttırır ve DNA metilasyonu, miRNA'lar ile epigenetik değişikliklere neden olur (Barajas-Olmos et al., 2019; Banerjee et al., 2019). Bazı enfeksiyonların da deri kanseri açısından risk oluşturduğu bilinmektedir. HIV pozitif bireylerde BHK riski yaklaşık 2 kat, SHK riski yaklaşık 5 kat artmış olarak bulunmuştur (Omland et al., 2018). Chen ve ark. (2019) ise HIV enfeksiyonunun insan epigenetik haritasında değişikliğe neden olduğunu bildirmiştir. Beta HPV tipleri, UV gibi karsinojenlerin etkilerini arttırarak BHK,SHK gelişiminde rol oynar (Tommasino 2017). HPV pozitif baş-boyun SHK'larında mikroRNA'ların rolü gösterilmiştir (Sannigrahi et al., 2018). Kullandığımız ilaçlardan bazıları da deri kanseri için risk faktörü olabilmektedir. Yapılan metaanalizde TNF-alfa inhibitörleri ile tedavi edilen romatoid artritli hastalarda melanom riskinin artmış olabileceği bulunurken (Olsen et al., 2016); Lin ve ark. (2017) TNF-alfa inhibitörlerinin epigenetik modifikasyonlara neden olduğunu bildirmişlerdir. Deri kanseri için risk oluşturabileceği iddia edilen bir diğer ilaç statinlerdir. Uzun süreli statin kullanımı erkeklerde artmış BHK riski ile ilişkilendirilmiş başka bir çalışmada ise statinlerin histon deasetilaz aktivitesini inhibe ettiği, farklı mikroRNA'ların ifadesini etkilediği tartışılmıştır (Lin et al., 2018; Allen and Mamotte, 2017).

Bütün bu bilgiler 1şığında epigenetik değişikliklerin deri kanserinde rol oynadığını ve bu epigenetik değişikliklere neden olan birçok çevresel risk faktörü bulunduğunu görmekteyiz. Bu risk faktörlerinden uzak durmak DNA'mızdaki epigenetik değişiklikleri de önleyebilecektir.

\section{Kaynaklar}

Greenberg, E.S., Chong, K.K., Huynh, K.T. et al. (2014). Epigenetic biomarkers in skin cancer. Cancer Lett. 342, 170-177.

Kürekçi, G.K., Bunsuz, M., Önal, G. et al. (2017). Kazanılmış Epigenetik Değişikliklerin Kalıtımı Ve Hastalıklara Yatkınlıktaki Rolü. İst Tip Fak Derg. 80, 45-53.

Saha, K., Hornyak, T.J., Eckert, R.L. (2013). Epigenetic cancer prevention mechanisms in skin cancer. AAPS J. 15, 1064-1071.

Sang, Y., Deng, Y.(2019. Current insights into the epigenetic mechanisms of skin cancer. Dermatol Ther. 32, e12964.

Moran, B., Silva, R., Perry, A.S. et al. (2018). Epigenetics of malignant melanoma. Semin Cancer Biol. 51, 80-88.

Guo, Y., Long, J., Lei, S. (2019). Promoter methylation as biomarkers for diagnosis of melanoma: A systematic review and meta-analysis. J Cell Physiol. 234, 7356-7367.

Murao, K., Kubo, Y., Ohtani, N. et al. (2006). Epigenetic abnormalities in cutaneous squamous cell carcinomas: frequent inactivation of the RB1/p16 and p53 pathways. Br J Dermatol. 155, 9991005 .

Brinkhuizen, T., van den Hurk, K., Winnepenninckx, V.J. et al. (2012). Epigenetic changes in Basal Cell Carcinoma affect SHH and WNT signaling components. PLoS One. 7, e51710.

Audia, J.E., Campbell, R.M. (2016). Histone Modifications and Cancer. Cold Spring Harb Perspect Biol. 8, a019521.

Penta, D., Somashekar, B.S., Meeran, S.M. (2018). Epigenetics of skin cancer: Interventions by selected bioactive phytochemicals. Photodermatol Photoimmunol Photomed. 34, 42-49.

Flørenes, V.A., Skrede, M., Jørgensen, K., et al. (2004). Deacetylase inhibition in malignant melanomas: impact on cell cycle regulation and survival. Melanoma Res. 14, 173-181.

Lee, J.J., Murphy, G.F., Lian, C.G. (2014). Melanoma epigenetics: novel mechanisms, markers, and medicines. Lab Invest. 94, 822-838. 
Garcia-Peterson, L.M., Ndiaye, M.A., Singh, C.K. et al. (2017). SIRT6 histone deacetylase functions as a potential oncogene in human melanoma. Genes Cancer. 8, 701-712.

Ceol, C.J., Houvras, Y., Jane-Valbuena, J. et al. (2011). The histone methyltransferase SETDB1 is recurrently amplified in melanoma and accelerates its onset. Nature. 471, 513-517.

Felicetti, F., Errico, M.C., Bottero, L. et al. (2008). The promyelocytic leukemia zinc fingermicroRNA-221/-222 pathway controls melanoma progression through multiple oncogenic mechanisms. Cancer Res. 68, 2745-2754.

Nguyen, T., Kuo, C., Nicholl, M.B. et al. (2011).Downregulation of microRNA-29c is associated with hypermethylation of tumor-related genes and disease outcome in cutaneous melanoma. Epigenetics. 6, 388-394.

Grignol, V., Fairchild, E.T., Zimmerer, J.M. et al. (2011). miR-21 and miR-155 are associated with mitotic activity and lesion depth of borderline melanocytic lesions. Br J Cancer. 105, 1023-1029.

Toll, A., Salgado, R., Espinet, B. et al. (2016). MiR-204 silencing in intraepithelial to invasive cutaneous squamous cell carcinoma progression. Mol Cancer. 15, 53.

Kennedy, C., Bajdik, C.D., Willemze, R. et al. (2003). The influence of painful sunburns and lifetime sun exposure on the risk of actinic keratoses, seborrheic warts, melanocytic nevi, atypical nevi, and skin cancer. J Invest Dermatol. 120, 1087-1093.

Whiteman, D.C., Whiteman, C.A., Green, A.C. (2001). Childhood sun exposure as a risk factor for melanoma: a systematic review of epidemiologic studies. Cancer Causes Control. 12, 69-82.

Narayanan, D.L., Saladi, R.N., Fox, J.L. (2010). Ultraviolet radiation and skin cancer. Int J Dermatol. 49, 978-986.

Yang, Y., Wu, R., Sargsyan, D. et al. (2019). UVB drives different stages of epigenome alterations during progression of skin cancer. Cancer Lett. 449, 20-30.

Archier, E., Devaux, S., Castela, E. et al. (2012).Carcinogenic risks of psoralen UV-A therapy and narrowband UV-B therapy in chronic plaque psoriasis: a systematic literature review. J Eur Acad Dermatol Venereol. 26, 22-31.

Nijsten, T.E., Stern, R.S. (2003). The increased risk of skin cancer is persistent after discontinuation of psoralen+ultraviolet A: a cohort study. J Invest Dermatol. 121, 252-258.

Maiorino, A., De Simone, C., Perino, F. et al. (2016). Melanoma and non-melanoma skin cancer in psoriatic patients treated with high-dose phototherapy. J Dermatolog Treat. 27, 443-447.

Nilsen, L.T., Hannevik, M., Veierød, M.B. (2016). Ultraviolet exposure from indoor tanning devices: a systematic review. Br J Dermatol. 174, 730-740.

Autier, P., Doré, J.F. (2019). Ultraviolet radiation and cutaneous melanoma: a historical perspective. Melanoma Res.

Li, C., Athar, M. (2016). Ionizing Radiation Exposure and Basal Cell Carcinoma Pathogenesis. Radiat Res. 185, 217-228.

Miousse, I.R., Kutanzi, K.R., Koturbash, I. (2017). Effects of ionizing radiation on DNA methylation: from experimental biology to clinical applications. Int J Radiat Biol. 93, 457-469.

Vienneau, D., de Hoogh, K., Hauri, D. et al. (2017). Effects of Radon and UV Exposure on Skin Cancer Mortality in Switzerland. Environ Health Perspect. 125, 067009. 
de Vocht, F., Suderman, M., Ruano-Ravina, A. et al. (2019). Residential exposure to radon and DNA methylation across the lifecourse: an exploratory study in the ALSPAC birth cohort. Version 2. Wellcome Open Res.

Puri, P., Nandar, S.K., Kathuria, S. et al. (2017). Effects of air pollution on the skin:A review. Indian J Dermatol Venereol Leprol. 83, 415-423.

Silva, I.R., Ramos, M.C.A.S., Arantes, L.M.R.B.et al. (2019). Evaluation of DNA Methylation Changes and Micronuclei in Workers Exposed to a Construction Environment. Int J Environ Res Public Health. 16.

Ortiz, A., Grando, S.A. (2012). Smoking and the skin. Int J Dermatol. 51, 250-262.

Wu, W., Liu, H., Song, F. et al. (2016). Associations between smoking behavior-related alleles and the risk of melanoma. Oncotarget. 7, 47366-47375.

Jones, M.S., Jones, P.C., Stern, S.L. et al. (2017). The Impact of Smoking on Sentinel Node Metastasis of Primary Cutaneous Melanoma. Ann Surg Oncol. 24, 2089-2094.

Joehanes, R., Just, A.C., Marioni, R.., et al. (2016). Epigenetic Signatures of Cigarette Smoking. Circ Cardiovasc Genet. 9, 436-447.

Barajas-Olmos, F.M., Ortiz-Sánchez, E., Imaz-Rosshandler, I. et al. (2019). Analysis of the dynamic aberrant landscape of DNA methylation and gene expression during arsenic-induced cell transformation. Gene. 711, 143941.

Banerjee, N., Das, S., Tripathy, S. et al. (2019). MicroRNAs play an important role in contributing to arsenic susceptibility in the chronically exposed individuals of West Bengal, India. Environ Sci Pollut Res Int. 26, 28052-28061.

Omland, S.H., Ahlström, M.G., Gerstoft, J. et al. (2018). Risk of skin cancer in patients with HIV: A Danish nationwide cohort study. J Am Acad Dermatol. 79, 689-695.

Chen, L., Zhang, S., Pan, X. et al. (2019). HIV infection alters the human epigenetic landscape. Gene Ther. 26, 29-39.

Tommasino. M. (2017). The biology of beta human papillomaviruses. Virus Res. 231, 128-138.

Sannigrahi, M.K., Sharma, R., Panda, N.K. et al. (2018). Role of non-coding RNAs in head and neck squamous cell carcinoma: A narrative review. Oral Dis. 24, 1417-1427.

Olsen, .CM., Hyrich, K.L., Knight, L.L. et al. (2016). Melanoma risk in patients with rheumatoid arthritis treated with tumour necrosis factor alpha inhibitors: a systematic review and metaanalysis. Melanoma Res. 26, 517-23.

Lin, Y.C., Lin, Y.C., Huang, M.Y. et al. (2017). Tumor necrosis factor-alpha inhibitors suppress CCL2 chemokine in monocytes via epigenetic modification. Mol Immunol. 83, 82-91.

Lin, B.M., Li, W.Q., Cho, E. et al. (2018). Statin use and risk of skin cancer. J Am Acad Dermatol. 78, 682-693.

Allen, S.C., Mamotte, C.D.S. (2017). Pleiotropic and Adverse Effects of Statins-Do Epigenetics Play a Role? J Pharmacol Exp Ther. 362, 319-326. 